\title{
Understanding co-creation within the public open space development process
}

\author{
Barbara Goličnik Marušić [0000-0002-3808-0187], \\ Urban Planning Institute of the Republic of Slovenia, Ljubljana. barbara.golicnik-marusic@uirs.si \\ Ina Šuklje Erjavec [0000-0002-9319-8380], \\ Urban Planning Institute of the Republic of Slovenia, Ljubljana. inas@uirs.si
}

\begin{abstract}
Co-creation as an approach has gained increasing interest from both urban planning scholars and practitioners, since it gives an added value of inclusiveness and stakeholder integration into the planning process. To effectively use the co-creation approach for planning and successful establishment of public open spaces it is important to closely relate and adjust it to the different stages of the spatial development timeline. In the chapter, in-depth understanding of the relationship between co-creation activities and the spatial planning and development process of POS is presented with possible benefits as well as obstacles explained. The focus is on defining the comprehensive structure of interlinks and detailed explanation of supportive co-creation activities with the aim to give the useful background for mutual understanding between urban planning professionals and different stakeholders related to urban open space development for quality of life and environment.
\end{abstract}

Keywords - Co-creation, public open space, participatory process, urban planning process, spatial development 


\section{INTRODUCTION}

This chapter addresses theoretical work conducted within the Project C3Places using ICT for Co-Creation of inclusive public Places. It explores co-creation as an open space planning and design tool to understand relations among actors as well as to recognise actual characteristics of the process and roles of the players. The work discussed here represents the initial phase of the research addressing theoretical backgrounds and first preliminary findings about key players in co-creation process (experts and participants) and their characteristics in relation to the stages of the process itself.

In the last couple of decades increased public engagement activities (e.g. participation, collaboration, co-creation) have been noticed in the field of urban development. It has been stimulated since 1980ies when a paradigm of communicative or collaborative planning has dominated theoretical discourse (e.g. Allmendinger and Tewdwer-Jons, 2002) and has entranced the field of strategic spatial strategy making by exploring the potentials of at the time new ideas about public argumentation and communicative policy practice developing (e.g. Healey, 1996). This practice shows that variety of activities and actions was understood as participatory also in the context of urban planning, design and well-being (e.g. Atkinson, 2003; Creighton \& Creighton, 2008; Jones \&Wells, 2007; Sanders \& Stappers, 2008) and that there is not enough critical view on that. Fors et al. (2015) in their analytic review of implementation of participation in urban green space development argue that many arguments for participation are taken for granted. They are especially concerned with the direct benefit participation may have in urban green space, pointing that, most of the empirical studies tested process benefits to users and administrators, rather than assessing the physical outputs of participation, and stress further, that because of these process-driven studies it remains unclear whether participation actually improves green spaces (Fors et al., 2015). However, physical participatory activities concerning public open spaces often resulted in a sort of make-up of places or end up as installation performance. Such engagements and results seem far away from what co-creation process is about to deliver. Although for the political happiness such results may often be recognised as co-creation achievement, but from urban planning and urban governance perspective such achievements should be questioned.

In any kind of participatory process, for planners and designers, it is crucial to be informed also from actual effects of different active participation activities on spatial development quality and how outcomes of co-creation processes could improve physical appearance of (changes in) places. Therefore, there is a challenge to explore the entire space development process including entrance and exit points of participatory activities their manner and expected results, to understand why final achievements may still too often diverge or miss provision of conducive places enhancing quality of life. According to reviewed literature by Fors et al. (20I5) connections 
between legitimacy in government and strong user voices which shall provide a base for better green space administration, which then in turn shell improve the physical quality of green space, were rarely detailed empirically. Thus, the considerable focus on testing human actor benefits could be worrisome, as well as valuation or contribution to physical green (public open) space quality are difficult to grasp.

In such circumstances this chapter reviews and comments on processes of participation and co-creation, and tries to recognise the roles planners, designers, public authorities as well as involved citizens may play that comprehensive results promised by co-creation activities may be as thoroughly achieved as possible. At the same time, from urban planning perspective for public open space development process, it is also examining how to achieve the optimal balance between expertise and participatory parts of this process, discussing when co-creation is the most appropriate and useful to improve outcomes of different process's steps and results. It seeks for optimal concept of co-creation types and interventions. Accordingly, part 2 provides a theoretical framework questioning especially (new) roles of actors in co-creation process, whereas part 3 addresses usage-spatial characteristics as immanent properties of public open places and outlines co-creation model for public open space development process, emphasising concrete experts' and participants' roles and their positions within this process.

\section{THEORETICAL FRAMEWORIS}

For successful implementation of the co-creation concept in public open space development processes there is a need to firstly examine background framework(s) of participatory activities related to urban planning. Hedensted Lund (2017) examining co-creation and participation as processes, shows possible linkages between them and points on their roots and therefore potentials they may have for urban planners. Summing up after Hedensted Lund (2017) public participation addresses issues of inequality of rights and power in society. On this basis in urban governance a socially oriented standard emerged. Several initiatives to engage and empower local citizens (Boonstra \& Boelens, 20I I), as well as concepts addressing and dealing with overcoming of social exclusion (e.g. public-private partnerships and networks for example in urban (re)development processes), provide a space for actual participation. More generally, a so-called concept of social innovation (e.g. Gerometta et al., 2005) emerged as an urban agenda in which social exclusion can be obviate through bottom-up processes. According to Hedensted Lund (2017) such atmosphere was pleasant for emergence of various initiatives, i.e. self-organised civic engagement which is not requiring only rights or power but goes for acting and enabling, and in such circumstances, participation becomes co-creation.

Content-wise evolutionary, co-creation in urban development partly builds on knowledge and experience from processes of innovation in the private sector, partly on the communicative turn in planning theory (e.g. Healey, 1996), and partly on the 
social innovation movement and its frames. Accordingly, in private sector, the notion of co-creation draws on methods to involve users in the development of goods or services and the creation of value. In public sectors co-creation as a method or approach often serves as a strategy for addressing complex societal problems, where the focus is most often on resources and the ability to solve problems rather than on inclusiveness, representation and empowerment of citizens. As examined by Hedensted Lund (2017) the studies of co-creation in a public sector context tend to be concerned with generating knowledge about citizens and their experiences with public services to provide a better problem identification for professionals to act on, rather than creating processes through which citizens themselves invent or articulate new services or products of public value and new ideas about which institutional structures may support such activities. Citizens tend to participate as individuals and not as representatives of groups or communities.

As shown, the co-creation concept in urban planning and urban governance is a conglomerate of ideas and norms coming from varied disciplines and practices, i.e. from marketing, public service management, to design and innovation. Perhaps therefore it does not share a very sharped and clear definition, however there are a few characteristics immanent to the process which in any circumstances define it. Such definition addresses decision making rights of people, innovation and value creation via collaborative process involving several types of actors, having a potential for overcoming the limitations of time and geography and allowing a significant leap in the influence of public involvement (e.g. Leading Cities, 2014).

Boonstra \& Boelens (20II) argue the ways and moods participatory activities have been conducted since the communicative turn, emphasising especially that processes have been initiated and controlled by public authorities, causing them to be time-consuming, subordinated to political systems working through a decision hierarchy and formalised structures of influence, and affected by an insufficient distribution of authority and responsibility. The problem in such implementation is that more spontaneous citizen initiatives and informal solutions to problems are excluded as these processes enable merely professional citizens or expert citizens to act effectively within the specific framework. Initially in co-creation process citizens are clearly valuable contributors to the process, but the practice showed that their precise role is rather unclear. The questions are how and when they can be involved?

\section{The roles of users/citizens}

The literature review shows that when participation is conceptualised as co-creation in urban planning processes, citizens are to be granted an active role. In the last decade, living lab is a popular concept, which again, similarly as co-creation process itself, is not clearly defined. However, there are several characteristics to be matched when implementing living lab either as a method or as a milieu for co-creation. They are as follows: citizen and user involvement, multiple actors' collaboration to 
innovate and create a (new) public value based on complementary knowledge, skills and resources implemented in a real-life experimentation etc.

The role citizens can have in co-creation is against the literature (e.g. Voorberg et al., 20I4, Fors et al., 2015) mostly recognised in three dimensions: co-implementers, co-designers, co-initiators. Accordingly, the role of co-implementer refers to activities in which citizens are important in making an activity or service work, but do not have a role in the initiation or design of a service or activity. Characteristic of such role is that it does not impose too great demand of user, therefore it is more probable that a wide spectrum of citizens participates. However, it is not clear how such role complements the search for solving complex problems, as it can be very probable, that the problem to be solved, is not clearly defined yet in the stage when such role of user is activated. However, this co-implementer role the most probably reflects a sort of replay on a provided issue rather that active engagement in issue provision. Therefore, it seems the most passive among the roles.

The role of co-designer mostly refers to processes initiated by public actors in which citizens are involved in development of a service or place. In comparison to co-implementer role, the demands of citizen are grater, usually addressing time consumption, competences and collaborative capabilities. In practice this role is often exemplified by living labs. Due to very broad understanding of living labs and/or weak competences for living lab implementation, citizens as co-creators are still often understanding as users of services, which means that information about them and their experiences with public services may be primary focus, therefore they are not necessarily grant a very active role. The role of co-initiator describes the most active and resource-demanding citizen role. According to Hedensted Lund (20I7) it draws on social innovation and social entrepreneurship and is illustrated as citizens who are self-organised and take the initiative to address a perceived problem, after which they collaborate with public authorities to do so. Simplified values of these characteristics of the roles a user or citizen can play in co-creation process are shown in Fig. I.

\begin{tabular}{|c|c|c|c|}
\hline \multirow[t]{2}{*}{ IMPLICAT } & \multirow[b]{2}{*}{ DEMAND } & \multirow[b]{2}{*}{$\begin{array}{l}\text { POSSIBLE RATE OF } \\
\text { PARTICIPATION }\end{array}$} & \multirow[b]{2}{*}{$\begin{array}{c}\text { ADDITION TO PROBLEM } \\
\text { SOLUTION }\end{array}$} \\
\hline & & & \\
\hline CO-IMPLEMENTER & Low & High & Low** \\
\hline CO-DESIGNER & High & Low* & High \\
\hline CO-INITIATOR & High & High & $\operatorname{High}^{* * *}$ \\
\hline
\end{tabular}

Fig. I: Characteristics of citizens' roles in co-creation process. Source: Goličnik Marušić, 2018.

These core characteristics of each defined significant role a citizen may play in a participatory process refer to two crucial questions regarding operability of 
co-creation as a process: When in a process citizen are active and how active they are? However, for urban planning and development process activities in addition to this it is of key importance in what way the users are involved and how the results of their activities can be used effectively? Therefore, there is a challenge to explore these roles of citizens in a participatory or co-creation processes further and redefine them in the context of public open space development, from the initial reasoning about places to their final physical appearance, usage and maintenance.

The examples on which the mentioned citizens' roles were characterised often come from the field of urban governance where through co-creation processes users are most likely addressed as a source of information about their habits and needs rather than as those who can also actually act, e.g. propose and debate. A comparison of these roles discussed above and summarised in Figure I regarding their implementation in the planning-development process shows weak and strong points for each role and calls for their adjustments to spatial planning and development practice.

In this sense the role, when user in involved as the one who react or replay on a given situation or in relation to a simple choice (YES/NO, better/worse), where a demand to participate is not high and therefore likelihood that a wide spectrum of citizens participation is called reacting/declaring. Another role, in which a citizen/user is more active and is usually involved upon some experts' proposals/scenarios are grounded and based on his/her experiences and expectations the user is actively involved in all further steps of the process, from re-defining scenarios, decision-making even in actual involvement in physical implementation of a place design, such engagement is called co-designing. In the situation where the user/citizen is active from the very beginning, for example, coming with an initiative for improvement, new arrangement etc. via all other steps as characteristics for involvement of a so-called co-designer, to the very final step of urban open space provision, usage and maintenance, such role is defined as co-creating. Adjustment of general roles and their characteristics (summarised after literature review and shown in Fig. I) is illustrated in Fig. 2.

\begin{tabular}{|c|c|c|c|c|}
\hline IMPLICATION & DEMAND & $\begin{array}{l}\text { POSSIBLE RATE OF } \\
\text { PARTICIPATION }\end{array}$ & $\begin{array}{c}\text { ADDITION TO } \\
\text { PROBLEM SOLUTION }\end{array}$ & $\begin{array}{l}\text { ROLE IN SPATIAL } \\
\text { PLANNING \& } \\
\text { I DEVELOPMENT } \\
\text { PROCESS }\end{array}$ \\
\hline CO-IMPLEMENTER - & سمل & High & Lam** & REACTING/DECLARING \\
\hline CO-DESIGNER & +imgtr & town & Hingh & CO-DESIGNING \\
\hline CO-INITIATOR & ताहा & III & 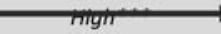 & CO-CREATING \\
\hline
\end{tabular}

Fig. 2: Citizen's roles in spatial planning and development process. Source: Goličnik Marušić and Šuklje Erjavec, 2018. 


\section{The roles of planners}

In co-creation process, especially, where citizens act as co-designers or co-creators is the role of planner in the processes significantly changing, too. It shifts from being the merely an expert making strategies and drawing plans to becoming also facilitator of the processes. The new task is characteristic for an ability to take a leadership for navigation in a process of shard power and voluntary engagement of lay people, who cannot be ordered to collaborate, but convinced of the merits of collaboration. The literature so far recognises three typical roles a planner must getting familiar with to be able to facilitate collaboration: a steward, a mediator, a catalyst.

Accordingly, the steward is a role, which is important in the initial phases of a collaborative process. It is characteristic for establishment and maintenance of the integrity of the process itself. Usually the steward is perceived as neutral, ensuring inclusivity and transparency, and moves the process forward. The mediator is a role, which entrance the floor when actual issues got addressed. The most significant activities reflect on conflict management and arbitering, as the mediator is a person, who nurtures the relations and builds trust among participants. It is however very beneficial being knowledgeable in spatial planning and design professions as, as such, particularly the steward can better direct the process, and the catalyst, skilled in planning and design can focus on seeking out and communicating opportunities for value creation and mobilises participants to pursue these opportunities.

\begin{tabular}{|c|c|c|c|c|c|c|}
\hline & $\begin{array}{l}\text { POSSITION } \\
\text { IN THE } \\
\text { PROCESS }\end{array}$ & $\begin{array}{l}\text { PROCESS PHASE } \\
\text { CHARACTERISTICS }\end{array}$ & $\begin{array}{l}\text { SKILLED IN } \\
\text { UP\&UD } \\
\text { KNOWLEDGE }\end{array}$ & ENGAGEMENT & PROVISION & TYPE OF WORK \\
\hline STEWARD & Early & SEARCH FOR ISSUES & ++ & Neutral & $\begin{array}{l}\text { INTEGRITY OF } \\
\text { THE PROCESS }\end{array}$ & $\begin{array}{l}\text { Establishment and } \\
\text { maintenance of the } \\
\text { process }\end{array}$ \\
\hline MEDIATOR & Mid & $\begin{array}{l}\text { ISSUES ADDRESSED } \\
\text { AND PROCEED }\end{array}$ & - & Incorporative & $\begin{array}{l}\text { NURTURING } \\
\text { RELATIONS AND } \\
\text { BUILDING TRUST }\end{array}$ & $\begin{array}{l}\text { Conflict } \\
\text { management and } \\
\text { arbitering }\end{array}$ \\
\hline CATALYST & Finall & $\begin{array}{l}\text { SOLUTIONS } \\
\text { PROVISION AND } \\
\text { VALUATIONS }\end{array}$ & ++ & Neutral & $\begin{array}{l}\text { PURSUIT } \\
\text { OPPORTUNITIES } \\
\text { AND VALUE } \\
\text { CREATION }\end{array}$ & $\begin{array}{l}\text { Seeking out } \\
\text { solutions and } \\
\text { communicating } \\
\text { opportunities }\end{array}$ \\
\hline
\end{tabular}

Fig. 3: Characteristics of planners' roles in co-creation process. Source: Goličnik Marušić and Šuklje Erjavec, 2018.

For planner these roles may be totally new and require a very different set of skills from what has traditionally been called for in planning. The roles of steward and catalyst may be familiar to the traditional planners and designer, whereas a mediator role requires quite new skills. They may also require a change of mindset and professional culture, which may be quite challenging.

As the chapter focuses on the co-creation in the urban open space development process, the core focus is on relationships among experts such as planners, designers 
and potential users. The role of public authorities is not examined into greater detail. However, to illustrate a simplified and general frame of this process, one may speculate that perhaps public authority is more of a steward, or even taking the role which assist this position of a steward. In such new situation the role of public authorities may shifts from that regulating state to the one enabling state, with emphasis on providing the opportunities, arenas, and power for civic networks to form and act (e.g. Sirianni, 2009).

In relation to characteristic roles planners/designers can take in co-creation planning/ design processes Zammit and Šuklje Erjavec (2016) firstly stress that the process viewpoint typically relates to other ancillary processes that accompany the design at different stages, including broader planning, community, environmental and sociocultural processes; and secondly, following Zammit (20I3), that in such frame/ context the development management process together with forward planning (policy-making) are crucial interrelated determinants which have a strong bearing on design outcome and quality; and finally highlight that the two-way relationship between the design process and other processes further reinforces the central role of urban designers, taking on a number of different forms. Interestingly, they (Zammit and Šuklje Erjavec, 2016) stress three significant roles, which they see immanently interlinked with the expert knowledge, for urban open space issues, especially grounded in place-making principles addressing spatial quality: enabler/facilitator, advisor to planning policies, and coordinator of diverse planning aspects.

Zammit and Šuklje Erjavec (2016) in the context of co-creation process well enrol the new recognised roles of planners or designers (steward, moderator, catalyst) into expert's work description. According to them they are exemplified as:

- enablers/facilitators dealing with different stakeholders, providing an expert role to inform and empower local communities particularly for bottom-up interventions

- advisors to planning policies, injecting spatial quality considerations into policies and interfacing between spatial planning considerations and the physical interventions 'on the ground'; and

- coordinators of diverse planning aspects, providing a holistic vision for spatial quality and interlinking different development issues and other undertakings into comprehensive urban plans.

Considering these new roles acceptance, they can gradually be exploited for public value creation if planners and other public administrators manage to adjust their traditional roles of being expert and professional by embracing them as expert facilitators of collaborative processes. In such situation comparing to traditional pose they have so far, planners and particularly authorities lose a sort of ordered control over the final product (planned solution) and/or top-down regulated process. The questions are, are authorities and planners already ready to take this shifts in roles? 
Can they see themselves also as supporters of the process instead of those being principal? At the same time this represents a big challenge also for planning, landscape and architectural schools. Such co-creative approach brings both, positive as well as negative aspects. It is positive, that diverse types of citizens can get ability and opportunities to be involved in urban development and problem solving. On the other hand, as creation focuses on including relevant and sufficiently diverse knowledge on urban processes to create innovative solutions to complex problems, there is a danger in diminished focus on input legitimacy and power inequalities, putting authorities and planner significantly into a steward and catalyst roles. The research on relevant topics and relations among the actors in the co-creation processes explicitly show that normative content and implications of conceptualising participation as co-creation is needed (e.g. Hedensted Lund, 20I7; Fors et al., 20I5; van de Ven et al., 2016). And, as shown by Zammit and Šuklje Erjavec (2016) the expert knowledge is still crucial for navigating the entire process, therefore the new recognised roles are to become necessary additional skills of a planner or designer must have as they influence the attitudes planner or designer takes in this process, however they cannot replace the role expert knowledge and experiences from the field.

\section{CO-CREATION ACTIVITIES, SPATIAL PLANNING AND DEVELOPMENT PROCESS}

Focusing on co-creation, Fors et al. (2015) studied research addressing user participation in urban green space, pointing to two main phases of the entire planning and development process: making phase - a stage where spaces are planned, designed and constructed; and keeping phase - a stage characteristics for ongoing work of maintenance and rehabilitation of existing spaces, including maintenance operations and systemic policy making. They distinguish also types of user engagement in any of the phases of the entire process: civic engagement characteristics for provision of inputs, involvement in negotiations, fundraising or even lobbying; and physical engagement, characteristics for involvement in actual physical site related actions such as site construction, maintenance of vegetation etc.

According to Fors et al. (20I5), civic participation is the most studied. They also point out that particularly low number of articles tested direct benefits to urban green space empirically. These authors argue, that participation to date remains little tested against physical outputs from green spaces and that the empirical work today has primarily focused on benefits to users and administrators rather than physical outputs of participation. They argue further that, administrative and process-oriented aspects of participation overshadow research's potential to critique and understand the physical outcomes of participation in urban green space development. Especially, as they found a great deal of vague rhetoric about wideranging benefits of participation without being empirically tested against reality in specific contexts. 
In order to improve physical green space quality and considering the essence of co-creation and benefits of urban green space for citizens, user participation activities should be developed and tested against the practical needs of green space development. Accordingly, while it is implicitly agreed that participation is good and capable of improving green spaces, more proof is needed to understand the mechanisms by which participation affects physical green space quality. In this relation, Fors et al. (20I5) up-grade Randrup \& Parsson (2009) model addressing analytical framework for understanding participation in green space development framing three: dimensions user, administration and public urban green space. The model originally sees interrelations between users and administration and then impact from administration to green space from which then there is benefit for the user. According to Fors et al. (20I5), adaptation of the model recognises active roles of users towards the green space and sees direct impacts on green spaces through physical participation and suggests implementation of user involvement place-based approaches for new modes of governance. Such viewpoint corresponds with Šuklje Erjavec and Ruchinskaya (2019), who argue for complex understanding of co-creation of places, which is going beyond merely civic participation, and pointing out also physical participation.

Whereas the urban open spaces are defined by its usage-spatial characteristics, represented by the activities, habits, attitudes and perceptions of people as well as the physical setting, features and elements forming a particular place, the presence or absence of people reflects the character and spirit of a place. As such it influences its usage-based characteristics and attractiveness for occupancy and forms its experimental appearance (e.g. Thwaites and Simkins, 2007). In such context, according to Šuklje Erjavec and Ruchinskaya (2019) the concept of co-creation shall go beyond planning and design activities extending them to the area of implementation, use and management of place. Therefore, co-creation as a process must be based on expert planner/designer knowledge but requiring transparency and efficient supporting tools and methodologies for information and ideas flow among stakeholders, their interaction and mutual development of knowledge and skills.

\section{Structure and interlinks among co-creation activities, planning and implemen- tation phases of urban open space development}

As shown above, co-creation as a concept of urban open space development process must take into consideration also aspects of spatial setting and social functioning of space. Process-wise this requires an inclusion of all stages of the spatial development process and addresses all types of related collaborative activities (e.g. civic and physical participation in making as well as keeping stages of space development process). Involving citizens into implementation and management of real places opens dimension of actual doing, e.g. coproducing the physical spatial solutions, being involved in interventions, as well as in sharing values, identities, contents and messages in/about a place. 
To better understand different requirements for expert interventions and opportunities of participant roles in co-creation, the whole process of the public open space development can be structured into 4 categories of engagement: Discover, Debate, Decide and Do, as defined by the Four-D Model for Civic Engagement (Digital Engagement Cookbook, 2017). Šuklje Erjavec and Ruchinskaya (2019) upgrade this concept via wider understanding of possible acts of co-creation and setting up the timeline of the comprehensive spatial development process. By this approach it is possible to present and explain how different types of engagement activities could be effectively incorporated into different stages of the process, and what kind of expert support would be needed. For illustration, within the Discover stage, for example, different types of co-creation activities are possible. Participants could be actively engaged into defining problems and issues, goals and visions by themselves, facilitated either by experts or together with experts in a co-creation process, but also, they can be participating on a more passive way, only reacting to the experts' proposals by opinion making, choosing solutions etc. On the other hand, to set a good background and basis for the public open space development, it is crucial to prepare a suitable set of spatial and social analysis which require different expert knowledge and skills. Although all kinds of local community information and knowledge can represent a valuable empirical knowledge very much related to the community and/or place; and has therefore a great importance for the place planning, design and development process, it should support and not replace the expertise for suitable and successful development of solutions.

The concept is outlined in the schemata (Figure 4). It represents the significant stages of the process from both viewpoints (participant, expert) and merge them in the

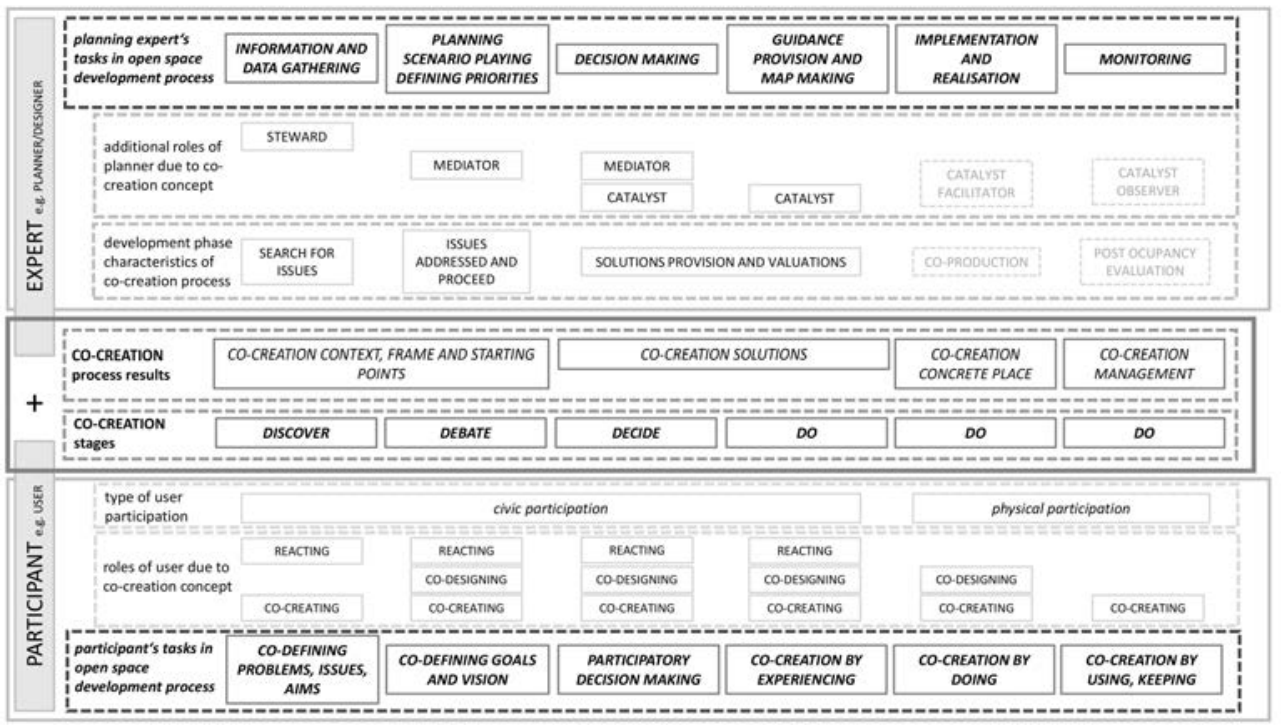

Fig. 4: Expert's and participant's characteristics vis-à-vis co-creation as open space planning and development process. Source: Goličnik Marušić and Šuklje Erjavec, 2018. 
middle line representing co-creation activities and results. The schemata as such do not simulate actual dynamic loops of the process, which remains further challenge to be addressed by the authors in the later stage of the project. It juxtaposes the two key groups of players (experts and participants) and their characteristics in relation to the stages of co-creation process.

\section{CONCLUSION}

There is no doubt, that the co-creation of public open space offers an excellent opportunity to actively engage different stakeholders in the process of the continuous everyday urban development. Such approach supports local community interactions that are important for quality of everyday life. Through active co-creation of living and working environment also the positive attitude, care and the sense of place is developed among people, as well as possibility of reducing common problems on spatial and social level of public open space, as for example vandalism, social exclusion and urban alienation.

However, it is very important to appropriately address all the complexities of such multi staged process by well-considered interlinking of different types of engagement activities with adequate expertise support in all phases of spatial development. In this way, positive outcomes of co-creation in public spaces exceed features of the final product, a spatial solution. There are many different types of collaboration activities, varying in intensities of citizen engagement depending on the issue addressed from sharing and interpreting information, co-learning, expressing opinions, defining priorities, refining ideas, making decisions, creating common values, implementing solutions, monitoring, etc. From place development perspective, they are all useful and important, but each with a different potential to fit in and support effectively different stages of the place development as such. Therefore, there is a further challenge in the C3Places project to develop a comprehensive insight and approach to address those issues. In this respect, it is also crucial to accept renewed role of expert(s), whether it is planner, designer or place keeper or manager. Original expert knowledge remains the key driver of the process and still represents the key source of knowledge upon which the new roles the experts shall play become additional skills to the original expert knowledge. Knowledge and content-wise the role is to be up graded but not replaced!

\section{REFERENCES}

Allmendinger, Ph. \& Tewdwer-Jons, M. (2002). The Communicative Turn in Urban Planning: Unravelling Paradigmatic. Imperialistic and Moralistic Dimensions. Space and Polity, 6(I): 5-24.

Atkinson, T., Cantillon, B., Marlier, E. \& Nolan, B. (2003). Social Indicators: The EU and Social Inclusion. doi:10.1093/0199253498.001.0001

Boonstra, B. \& Boelens, L. (20I I). Self-organisation in urban development: towards a new perspective on spatial planning. Urban Research and Practice, 4(2), 99- 122. 
Creighton \& Creighton, Inc. (2008). What is Public Participation? Retrieved from: http://www. creightonandcreighton.com.

Digital Engagement Cookbook (2017). Digital Engagement Cookbook, Methods Directory. Retrieved from: http://engagementdb.org

Fors, H., Molin, J. F., Murphy, M.A. \& van den Bosch, C. K. (2015). User participation in urban green spaces - For the people or the parks? Urban forestry and urban greening, 14: 722-734.

Gerometta, J. Häussermann, H. \& Longo, G. (2005). Social innovation and civil society in urban governance: Strategies for an inclusive city. Urban Studies, 42(I I), 2007-202I.

Healey, P. (1996). The Communicative Turn in Planning Theory and its Implications for Spatial Strategy Formation. Environmnet and planning B, 23(2): 217-234.

Hedensted Lund, D. (20I7). Co-creation in Urban governance: From inclusion to Innovation. Scandinavian journal of public administration, 22(2): 27-4I.

Jones, L., and Wells, K. (2007). Strategies for academic and clinician engagement in community - participatory partnered research. JAMA, 297(4): 407-410.

Leading Cities (2014). Co-Creating Cities: Defining Co-Creation as a Means of Citizen Engagement. Retrieved from: http://leadingcities20 I4.files.wordpress.com/2014/02/co-creation-formatted-draft-6.pdf Randrup, T. B. \& Parsson, B. (2009). Public green spaces in the norcdic countries: development of a new strategic management regime. Urban forestry and urban greening, 8: 3I-40.

Sanders E. B. N. \& Stappers, P. J. (2008). Co-creation and the new landscapes of design. CoDesign, 4(I): 5-18.

Sirianni, C. (2009). Investing in Democracy: engaging Citizens in Collaborative Governance. Washington, DC. Brookings Institution Press.

Šuklje Erjavec, I. and Ruchinskaya, T. (2019). A Spotlight of Co-Creation and Inclusiveness of Public Open Spaces. In Smaniotto Costa, C. et al. (Eds.). CyberParks - the interface between people, places and technology. Cham: Springer, 209-223

Thwaites, K. \& Simkins, I. (2007). Experiential Landscape: an approach to people, place and space. London: Routledge.

van de Ven, F. H. M., Snep, R. P. H., Koole, S., Brolsma, R. van derBrugge, R., Spijker, J. \& Vergroese, T. (2016). Adaptation Planning Support Toolbox: Measurable performance information based tools for co-creation of resilient, ecosystem-based urban plans with urban designers, decision-makers and stakeholders. Environmental Science and Policy, 66: 427-436.

Voorberg, W. H., Bekkers, V. J. J. M. \& Tummers, L. G. (2014). Systematic review of co-creation and co-production: Embarking on the social innovation journey. Public Management Review, 3 I (2): I-25.

Zammit, A. (20I3). Urban design quality through development control: the case of Malta. PhD thesis, University College London

Zammit, A. \& Šuklje Erjavec, I. (20I6). Allotment gardens as a challenge for an urban designer. In Bell, S. (ed.). Urban allotment gardens in Europe. New York: Routledge, 254-288. 